\title{
Alma sensible, romanticismo exaltado y suicidio. Sobre la novela Voyleano o la exaltación de las pasiones (1827), de Estanislao de Cosca Vayo y Lamarca
}

\section{Sensitive Soul, Romantic Extremes, and Suicide}

\author{
Russell P. Sebold* \\ Académico Correspondiente de la Real Academia Española
}

\section{RESUMEN}

El personaje Voyleano tiene modelos en el suicida Werther, de Goethe, y en el deseoso de morir Tediato de las Noches lúgubres, de Cadalso. Entran en la confección de la figura de Voyleano la nueva sensibilidad de la Ilustración, el dolor cósmico romántico y la exaltación de la psicología romántica. En la novela de Vayo se vive la invasión napoleónica de España, y tal ambiente se presta a seducciones libertinas, traiciones, grandes desilusiones y pérdida de la fe. Voyleano, como don Quijote, como Julien Sorel, como Emma Bovary y como varios personajes de Larra y Mesonero Romanos ha buscado un modelo o logos en un personaje anterior. Después de don Quijote, Voyleano es el primero de todos ellos. A Voyleano le parece poco noble y cobarde el acto físico del suicidio, y aunque se inspira en Werther, le atrae en Tediato el modo de suicidarse evitando el acto físico del suicidio.

Palabras Clave: sensismo, sexto sentido, sensibilidad, exaltación, dolor cósmico, seducción, logos, suicidio.

\section{ABSTRACT}

The character Voyleano has models in the suicide Werther, by Goethe, and in the death-desiring Tediato in the Lugubrious Nights, by Cadalso. The creation of the figure of Voyleano depends on the new sensibility of the Enlightenment, romantic cosmic grief, and the exaltation of romantic psychology. In the novel by Vayo the Napoleonic invasion of Spain is depicted, and this atmosphere lends itself to libertine seductions, betrayals, great disillusionments, and the loss of faith. Voyleano, like don Quijote, like Julien Sorel, like Emma Bovary, and like several characters from Larra and Mesonero Romanos has sought a model or logos in an earlier character. After don Quijote Voyleano is the first of all of them. Voyleano considers the physical act of suicide lacking in nobility and cow-

* Con el presente artículo, que aparece en estas páginas a título póstumo, Revista de Literatura expresa su reconocimiento al magisterio de Russell P. Sebold (1928-2014) y, especialmente, a su aportación al estudio de la literatura española, sobre todo del siglo XVIII. 
ardly, and although he is inspired by Werther, he is attracted to Tediato's way of committing suicide while avoiding the physical act of suicide. suicide.

Key words: sensism, sixth sense, sensibility, exaltation, cosmic grief, seduction, logos,

\section{ACLAREMOS LOS TÉRMinOS}

Leyendo las páginas sobre el siglo XVIII en las historias de la literatura española que imperaban hacia 1960, casi nos convencíamos de que Descartes había inventado la poética clásica. Pues en página tras página se invocaba la razón cartesiana para explicar las aspiraciones, el tono y el fracaso de los que en esas páginas no infrecuentemente se veían tildados de poetas y prosistas seudoclásicos a la francesa. La verdad es que ni Boileau en Francia ni Luzán en España soñaron jamás con una poética, una poesía o una literatura racionalista. Mas esos autores de manuales e historias de la literatura fueron tan persuasivos predicadores, que para algunos la voz razón todavía pasa por la palabra clave de las letras españolas del setecientos. En efecto, no hace sino tres o cuatro años que una conocida pero muy descarriada hispanista norteamericana me regañaba por haber dado una importancia excesiva al sentimiento en mis interpretaciones de las obras de Cadalso, y me recordaba que la musa de ese pobre siglo era la razón, la razón fría.

Una auténtica y más precisa palabra clave para la literatura del siglo XVIII - poesía, teatro, novela, ensayo-, así como para el paso a la mentalidad literaria decimonónica, es seguramente el sustantivo sensibilidad, o su correspondiente adjetivo sensible; voces que pertenecen a la misma familia léxica que sentido y sensismo. El manejo de los cinco sentidos corporales del hombre para la solución de problemas científicos en las obras de filósofos sensistas como Bacon, Hobbes, Fernán Núñez, Locke, Shaftesbury, Condillac y Rousseau reveló la existencia de miles y miles, millones y millones de detalles materiales nunca advertidos de nuestro mundo físico, y a la larga llevó, en la literatura, al realismo. Mas quienes en un principio se maravillaron de tantas novedades quedaron a la larga decepcionados, porque tanto pormenor físico de ningún modo ayudaba a aclarar los problemas morales y espirituales del hombre, y como consecuencia, en el siglo XVIII se empezó a especular sobre el llamado sexto sentido interior, sede de la sensibilidad y de todas las alegrías y cuitas del animal humano. Y merced al sexto sentido, en literatura, se abrieron tantas nuevas perspectivas psíquicas como vastas visiones materiales se habían revelado por los cinco sentidos originales ${ }^{1}$.

\footnotetext{
${ }^{1}$ Irá quedando cada vez más claro que es de género experimental la novela Voyleano o la exaltación de las pasiones, y experimentales y novedosas lo son de una manera u otra todas las doce novelas de Vayo. Voyleano no es su única novela realista de tema contemporáneo; se anticipa Vayo a las novelas históricas de los años treinta y cuarenta de su siglo,
} 
En la segunda época romántica, el doliente soldado, seductor y amante Voyleano sufriría inconmensurablemente debido a su sexto sentido y su sensibilidad. Le acompañaremos en sus más exquisitos martirios. Mas antes, recurriendo a testimonios fidedignos, dejemos establecido que sensibilidad o sensible es, en efecto, la palabra clave de la literatura de la Ilustración y la romántica. Son mías las cursivas en todos los ejemplos citados a continuación.

En sus Réflexions sur la poésie et sur la peinture, publicadas por vez primera en 1719, el abate Jean-Baptiste Dubos escribe: «C'est ce sixième sens qui est en nous, sans que nous voyions ces organes [...] C'est enfin ce qu'on appelle communément le sentiment»(Dubos, 1770: 342)2.

En sus Essays Moral and Political (1741-1742), David Hume escribe:

There is a certain delicacy of passion, to which some people are subject, that makes them extremely sensible to all the accidents of life [...] And when a person that has this sensibility of temper meets with any misfortune, his sorrow or resentment takes entire possession of him (Compact Oxford Dictionary, 1971: 2.728) ${ }^{3}$.

Es del padre Feijoo el sugerente ejemplo de 1753 que sigue:

Pocos son los que ignoran, o por lo que experimentan en sí mismos, o porque lo oyeron a otros, lo que pasa en los que tienen el corazón más sensible, o el alma más dispuesta, ya a los sentimientos de la ternura amatoria, ya de la compasión de los males ajenos, ya de la estimación afectuosa de las virtudes, o aversión a los vicios que reconocen en otros, cuando leen una comedia, una novela o cualquiera historia fabulosa; donde se representan con imágenes vivas, expresiones insinuantes y descripciones patéticas, sucesos ya prósperos, ya adversos; empeños o pretensiones, ya de feliz, ya de infeliz éxito, ya virtudes amables, ya detestables vicios (Feijoo, 1770: IV, 86).

En Julie ou la Nouvelle Héloïse (1761), de Rousseau, no hay solución del prohibido amor compartido por esta encantadora doncella y su maestro SaintPreux, y un día adolorido por la interdicción de tan dulce emoción, éste exclama: «O Julie! que c'est un fatal présent du ciel qu'une âme sensible!»

dedica otras novelas a resonantes sucesos contemporáneos, cultiva la novela femenina, la novela amorosa contemporánea, la novela de dandy, etc. Pensando en tantas novedades, Rodney Rodríguez escribe, en el estudio recogido en nuestra bibliografía: «Vayo, el hombre que podría haber sido recordado como el principal antecesor de la moderna novela española, porque fue el único escritor anterior a Fernán Caballero que experimentó con el género y produjo un número respetable de obras narrativas, es al contrario desconocido» (Rodríguez, 1988: 276).

${ }^{2}$ Traduzco: «Es este sexto sentido que está en nosotros, sin que veamos sus órganos. [...] Es en fin lo que se llama comúnmente el sentimiento».

${ }^{3}$ Citado entre los ejemplos del uso de la voz sensibility en el diccionario indicado. Traduzco: «Hay cierta delicadeza de pasión, a la que están sujetas algunas personas, la cual las hace extremadamente sensibles a todos los accidentes de la vida [...] Y cuando una persona que tiene esta sensibilidad de temperamento se encuentra con alguna desventura, su tristeza o resentimiento se posesiona enteramente de ella». 
(Rousseau, 1967: 53) . Todo de un modo u otro procede de los sentidos. Es un siglo materialista, mas de ningún modo exento de delicadeza de afectos. Cielo, Dios, rezar ya no son sino modos de decir para expresar estos afectos. Ya escucharemos ecos de las palabras de Saint-Preux en otros personajes y literatos apenados.

Encarcelado en la segunda de las Noches lúgubres, que Cadalso escribió en junio de 1771, Tediato escucha y reflexiona sobre lo que pasa en el calabozo vecino:

¡Qué silencio tan espantoso ha sucedido a los suspiros del moribundo! Las pisadas de los que salen de su calabozo, las voces bajas con que se hablan, el ruido de las cadenas que sin duda han quitado del cadáver, el ruido de la puerta estremecen lo sensible de mi corazón (Cadalso, 2008: 398).

Es de Torcuato, en El delincuente honrado (1773), de Jovellanos, la bella exclamación que sigue: «Si las lágrimas son efecto de la sensibilidad del corazón, ¡desdichado de aquel que no es capaz de derramarlas!» (Jovellanos, 2008: 110). Como colofón de esta obra, Jovellanos pone su propia versión de un trozo de la obra de Beccaria titulada De los delitos y las penas: «Dichoso yo [...], si he logrado inspirar aquel dulce horror con que responden las almas sensibles al que defiende los derechos de la humanidad» (ibid., 171). Entre 1774 y 1777, en la sevillana Imprenta de don Manuel Nicolás Vázquez y Compañía, Cándido María Trigueros publicó varios poemas largos de temática psicológica, entre los cuales figuran La desesperación, La ternura y La tristeza, síntomas de la nueva sensibilidad de la centuria decimoctava.

No olvidemos que ya Shaftesbury, en su rapsodia filosófica de 1709, The Moralists, llamó romántica a esta nueva sensibilidad (Cooper, 1964: II, 110). Mas sigamos con nuestra investigación cronológica de la nueva sensibilidad de los ilustrados y sus epígonos. En el tomo tercero (1788) de su Diccionario castellano, Terreros da una definición pertinente del sustantivo sensibilidad: «Ternura, blandura, disposición de los sentidos para recibir las impresiones de los objetos, cualidad de quien es sensible, o fácil para que le muevan las cosas, discursos, etc.» (Terreros, 1788: III, 467). En la tragedia La condesa de Castilla, de Cienfuegos, se oye un eco del fragmento de La Nouvelle Hélöise que hemos tomado en cuenta. Trátase del verso final del siguiente parlamento de la condesa: « ¡Ay! ¡plegue, Sancho, por tu paz y dicha, / plegue, hijo mío, al compasivo cielo / que no llores jamás como tu madre / de un alma tan sensible el don funesto» (Álvarez de Cienfuegos, 1798: I, 385) .

En La Eumenia, o la madrileña (1805), novela sentimental de Gaspar Zavala y Zamora, la heroína se halla abandonada y muy enferma, pero el

\footnotetext{
${ }^{4}$ Traduzco: «iOh Julia! ¡Es un fatal regalo del cielo un alma sensible!».

${ }^{5}$ Sobre esta tragedia puede consultarse mi estudio «La génesis del drama romántico: $L a$ condesa de Castilla, de Cienfuegos», en Sebold (2010a: 79-90).
} 
anciano Amelo la atiende como si fuera su hija. «Yo le rindo [al cielo], añadió ella, las más humildes gracias, porque en mi triste situación, me ha deparado el cariño de un varón tan sensible y virtuoso» (Zavala y Zamora, 1805: 22). En 1811, Jane Austen publica su novela Sense and Sensibility, cuyo título es de por sí una ilustración precisa del concepto que estudiamos en estas páginas preliminares, por cuanto se da una oposición completa entre las significaciones de los dos sustantivos de su título, ya que el primero es la voz operativa de la frase hecha common sense, o sentido común.

Vaya una curiosa muestra de una novela histórica epistolar, de tema decimonónico contemporáneo y antecedente de los Episodios Nacionales galdosianos, según explico en una crónica de $A B C$ de 1998 (Sebold, 2004: 503-507). La autora de estas Cartas de la reina Witinia fue la tercera mujer de Fernando VII y reina de España, María Josefa Amalia de Sajonia. El interés histórico de la obra es que con cierta objetividad la autora comenta el ambiente político del Trienio Constitucional y las humillaciones a las que fue sujetado su augusto pero inepto consorte. Hoy nos interesa, en cambio, un momento más nostálgico de sus reflexiones. Al escribir a su hermana, la princesa Fernandina, Witinia recuerda un hermoso paisaje fluvial: «asaltan a mi memoria imágenes tan sensibles, que mis ojos involuntariamente se bañan en lágrimas, y mi tristeza se aumenta de un modo que no te puedo ponderar» (Sajonia, 1822: 200).

Podríamos citar textos adicionales de sensible, sensibilidad en las novelas de Montengón, en las de García Malo, en La Leandra de Valladares de Sotomayor, en otras novelas del mismo tiempo, en otras comedias lacrimosas, o en la poesía de esos tiempos. Mas bastarán los ya reseñados, junto con las nuevas muestras que veremos en las páginas de Voyleano o la exaltación de las pasiones, al ir evolucionando en esta obra la simple sensibilidad hacia la exaltación de las pasiones. Haré una sola excepción, porque es del mismo Vayo y anterior a su primera novela. En sus Ensayos poéticos, el segundo terceto de cierto soneto es el siguiente: «La belleza se eclipsa en un momento; / mas pecho tal, una alma tan sensible / vencen al tiempo y su mudar impío» (Vayo, 1826: 88).

\section{PARÁmetros ARgumentales y AFINIDADES LITERARIAS}

Lamentablemente, escasean casi tanto los ejemplares de la edición moderna (2007) de Voyleano, realizada por Mark Malin, como los de la edición príncipe de 1827 (reeditada en 2011); y como es probable que el lector ignore totalmente el contenido de la novela de Vayo, he puesto aquí una sinopsis sucinta de su acción.

El año es 1812; vivimos la ocupación napoleónica de España. Voyleano es un joven libertino que se entrega gozosamente a todos los vicios que le 
brinda la Villa y Corte, mas pronto se desilusiona de esas bellas tentaciones y de la vida. Ha leído la famosa novela epistolar Werther, de Goethe, lectura que los demás personajes le censuran como demasiado fuerte y perniciosa. ¿No habrá leído también la Exercitatio philosophica de morte voluntaria, de Johann Robeck (1736), y las Noches lúgubres, de Cadalso? Voyleano sabe que por toda Europa los lectores jóvenes van eligiendo el mismo desenlace para sus penosas existencias que el suicida Werther; idea que le fascinará a lo largo de toda su historia, pero que no podrá poner por obra, ya que le parece cobarde y poco noble el acto del suicidio. Así se explica que en la triste trayectoria de su vida Voyleano buscará el modo de suicidarse sin de hecho cometer el acto físico del suicidio. En lo cual discerniremos la influencia de las Noches lúgubres (1771), de Cadalso 6.

En Madrid Voyleano seduce a la hermosa Leonor, hija de una familia respetable, quien muere de sobreparto, perdiéndose a la vez su hijo; material de espantosas apariciones que atormentarán al depravado protagonista. Voyleano es amigo y admirador de cierto Coronel, quien defiende los derechos del legítimo monarca español Fernando VII en la batalla, y por tanto no puede atender a las necesidades emocionales y materiales de su numerosa familia, a la cual el protagonista recoge y sostiene en su casa valenciana. Se enamoran Voyleano y la hija mayor del Coronel, Roberta, quien, sin embargo, teme a su amante, porque ella y la desventurada Leonor eran amigas íntimas. En cambio, la madre de Roberta hace todo lo posible por casar a su hija con un joven tan acaudalado, llegando a falsificar papeles para lograrlo. El antiguo amante de Roberta en Madrid, el ahora traidor y oficial del ejército francés, Bellsant, observa la boda desde un escondite, y hace aprisionar a los nuevos casados. El afrancesado intenta vengarse seduciendo a Roberta en la cárcel, y la afligida esposa de Voyleano no resiste a tantos pesares, no siendo otra la causa de su muerte que su gran sensibilidad. El adolorido viudo organiza un motín en la cárcel, defiende ardorosamente a Fernando VII delante de los soldados y oficiales franceses, rechaza una nueva oportunidad de confesarse y así, en cuanto hace, forzándoles la mano, exhala sus últimos alientos ante un pelotón de fusilamiento. He aquí el suicidio que ha logrado Voyleano sin de hecho cometer ese acto. Al traidor Bellsant le llevan preso en cadenas a Francia.

\footnotetext{
${ }^{6}$ Era inevitable la influencia de las Noches lúgubres. Entre 1802 y 1823 se estamparon dieciocho ediciones nuevas de las Noches lúgubres, tres de ellas en Valencia, patria de Vayo; y en el año de la publicación de Voyleano, 1827, sacóse otra. No era fácil que un joven sensible, apasionadamente dedicado a las letras y que un año antes de publicar su primera novela, había sacado un libro de versos, ignorara tan resonante fenómeno, uno de los primeros best-sellers, la presencia universal de las Noches lúgubres en la España literaria de esos días. Es más: una de las ediciones valencianas de las Noches lúgubres la estampó en 1817 Ildefonso Mompié, que pasando diez años publicaría la novela Voyleano, con el mismo formato que la obra de Cadalso.
} 
Voyleano es una novela epistolar como su modelo, el Werther de Goethe: su acción se narra en cuarenta y nueve cartas, escritas principalmente por su héroe titular, pero también por Roberta, doña Rosa, la madre de ésta, una baronesa amiga de la familia, un cura y Jerónimo, el íntimo amigo a quien Voyleano dirige sus cartas sobre sus malaventurados amores y su tétrica cosmovisión. En realidad, la novela contiene más de cincuenta cartas, porque algunos de los desconsolados corresponsales adjuntan cartas de otros testigos de la funesta acción. El ambiente de Voyleano varía entre el urbano y el rural, como el de la novela alemana. Werther cuenta sus decepciones amorosas con Carlota en las cartas que manda a su amigo Guillermo, como Voyleano lo hace con su amigo Jerónimo. El elemento de las familias tiene cierta importancia en ambas novelas, el de los clérigos mucha menos en las páginas de Goethe que en las de Vayo.

Algunos de los lectores de 1827 se veían tan profundamente afectados por los sensibles vaivenes de esta acción novelesca, que no se atrevían a firmar sus nombres en la lista de los suscriptores de Voyleano (impresa al final de ambas ediciones); pues al final del listado de los nombres de las señoras suscriptoras, una avergonzada y tímida lectora puso simplemente: «Una suscriptora». Sólo en esa época no sorprende que haya habido un suscriptor varón igualmente sensible, quien al final del listado de los señores suscriptores no se atrevió a poner sino «Un suscriptor».

¿Cómo se explica el nombre del protagonista, Voyleano? Para los españoles de principios del siglo XIX el apellido Werther resultaba muy exótico. Vayo quería otro igualmente misterioso para su héroe, y lo logró inspirándose en el nombre y apellido rumano Voilean, que puede haber oído a esos gitanos rumanos que vagaban siempre por toda Europa. Otros étimos menos parecidos que se han sugerido para el nombre de Voyleano son los nombres del científico inglés Boyle, del poeta y preceptista francés Boileau y del escritor de viajes francés Volney, contemporáneo de Vayo y su personaje.

En el presente apartado quédase por comentar un elemento que, por otra parte, resulta evidente a lo largo de las páginas de Vayo. Quien lee cartas históricas o una novela epistolar se identifica sin pensar con la hora actual del personaje histórico o novelístico. Estamos en su mundo, y como consecuencia no se nos ocurre cuestionar la realidad de lo que nos cuenta. La novela epistolar es, por tanto, un género esencialmente realista. Es más: Vayo apoya el realismo de su novela en la historia contemporánea de España: «Tomé pues el origen de la guerra de nuestra Independencia, y la enlacé con mi fábula, aumentando de este modo la verosimilitud» (Prólogo). Así se explica que las cartas de todos los personajes se fechen en el ya indicado año de 1812. De tal contemporaneidad e inmediatez procede la fuerza y el carácter inmediato y convincente de la emoción casi siempre exaltada de Voyleano. Vayo es principalmente conocido como novelista histórico: por ejemplo, La conquista de Valencia por el Cid (1831). Pero con su primera novela, Voyleano, así 
como con la segunda, Los terremotos de Orihuela, o Enrique y Florentina, historia trágica (1829), lo mismo que con alguna otra, Vayo apunta al período de realismo temprano, que he estudiado en mi libro En el principio del movimiento realista (2007). Es verdad que estamos a la par en pleno romanticismo, mas es también un periodo de notable fermentación durante el que se fraguan nuevas combinaciones de formas y géneros. Por ejemplo, en la novela realista Dos mujeres (1842), de Gertrudis Gómez de Avellaneda, se investigan los efectos psicológicos del romanticismo sobre una mujer ilusionada, que acaba suicidándose, siguiendo hasta cierto punto el ejemplo de Voyleano. Puede consultarse mi estudio sobre dicha novela de la Avellaneda, el cual está reseñado en la bibliografía (Sebold, 2010b) 7 .

\section{La exaltación de Voyleano. Antología de EJEMPlos}

Más bien que un frío análisis psicológico terciopersonal, prefiero la palabra viva, íntima, recelosa, trémula pero también ilusionada y arrogante del propio Voyleano, en su inseguro medio histórico y social. Más adelante razonaremos sobre el cúmulo de las revelaciones de Voyleano. Mas por de pronto vamos a observarle en el pleno efluvio de sus pasiones románticas. Nada tiene Voyleano que envidiar al Sturm und Drang — Tempestad y Empuje- que arrollaba a Werther. A continuación reúno ejemplos de la exaltación de Voyleano en su primera persona. En todos ellos está en plena ebullición emocional, mas de vez en cuando, en un como salto atrás, se percibe que el estado de ánimo que ahora caracteriza al protagonista de la novela de Vayo procede en un principio de su singular sensibilidad. Cito los ejemplos por los números de las cartas; pues no hay manera de saber a cuál de las ediciones de Voyleano — la antigua o la moderna- podrá tener acceso el lector. En los pasajes siguientes escribo en cursiva la voz «exaltación» y otras de la misma familia léxica, porque aparte de su función esencial en la caracterización de Voyleano, no hay que olvidar la evidente influencia de esta novelita sobre la aparición del término «romanticismo exaltado», que erróneamente no pocos críticos han supuesto ser emanación exclusiva de las obras de Espronceda. El yo en la inmensa mayoría de los pasajes citados a continuación es de Voyleano.

Cualquiera por medianos conocimientos que tenga, sabe los males que ha ocasionado a la Europa la lectura de la novela alemana, el Werther. Los suicidios han sido en grande número: se han creado con ella espíritus melancólicos e insociables, o han aparecido genios turbulentos que dotados de una imaginación feliz y algún

\footnotetext{
${ }^{7}$ Aunque de época posterior a la que estudiamos de momento, La Pródiga, de Pedro Antonio de Alarcón, es otra novela realista en la que se analizan los efectos psicológicos del romanticismo sobre una mujer sensible, quien es llevada por sus circunstancias al suicidio. Véase la bibliografía para mi artículo sobre esta obra (Sebold, 2011).
} 
talento mezclado de sensibilidad, nos han hecho conocer la exaltación de las pasiones (Prólogo de Vayo).

¿Y qué tienen que ver la elocuencia y la pintura con el fuego que me exalta? Son muy frías para representar lo que siento. No puedo seguir. Adiós (carta 1).

Más que todo, la tétrica soledad, que exalta el alma a regiones no conocidas, había hecho nacer en mí un entusiasmo novelesco (carta 2).

Mi exaltación de ideas crece de día en día, y cada instante encuentro mayor grado de sensibilidad en mí. Esclavizando los sentidos con los sentimientos vehementes que despierta en la inocente juventud, crea en nuestros corazones una enfermedad más peligrosa que la misma fiebre. Ésta se puede atajar, ipero aquélla es tan difícil si se toma incremento! ¡Concebir grandezas, y vernos cercados de humillaciones! (Carta 3).

Las emociones, los trasportes que acompañaban nuestra conversación, sólo tú, Jerónimo, puedes concebirlos porque los conoces. No lo dudes, somos de una complexión diferente de la general (carta 3).

A pesar de que me caracteriza una sensibilidad extremada y un corazón grande, mi conducta en la Corte es bastante reprensible (carta 4).

Mis ojos se vuelven a lo pasado, y leen escenas trágicas, cuyo actor principal soy yo (carta 4$)$.

Una simpatía secreta nos atrajo, y muy pronto nos amamos [Leonor y yo] con la vehemencia de dos héroes de novela, pues la historia de Abelardo y Heloísa nos acaloró de tal modo, que juramos imitarlos en todas sus acciones. Los imitamos, en efecto, querido amigo. Las más dulces horas se me deslizaban en el muelle lecho de la moderna Heloísa (carta 4$)^{8}$.

Juventud, loca juventud, ¡ cuántos crímenes osas cometer inocentemente, arrastrada de un loco entusiasmo! ¡Cuán precipitada corres al abismo de las pasiones! (carta 4).

Yo he vivido en la Corte, allí donde despliega su mágico manto el placer. $\mathrm{He}$ seguido mis propias sensaciones, he satisfecho el grito de mis sentidos (carta 5).

Yo venero mis errores, si es permitido explicarme así, puesto que ellos han despertado mi razón y encendido con mayor fuerza la antorcha de la sensibilidad. Ser sensible, tan sensible como yo es una desgracia ${ }^{9}$. ¡Pero es una desgracia que engendra un deleite lúgubre y tan dulce! (carta 6).

El hombre desnudo de pasiones, no es hombre; es un ser inanimado (carta 7).

Ved el fondo oscuro que forman los lejanos pinos y el tétrico horror que infunden los lúgubres cipreses. Las lágrimas del sauce llorón vedlas (carta 8).

${ }^{8}$ La frase «la moderna Heloísa», con que Vayo alude a Leonor, parece confirmar a la vez la influencia de la novela Julie, ou la Nouvelle Héloüse (1761), de Rousseau. Quienes leían el Werther (1774), de Goethe, habitualmente leían asimismo dicha ficción epistolar del gran literato suizo, en la que el personaje Lord Éduard Bomston diserta sobre el suicidio.

${ }^{9}$ Compárense estas palabras con las de Saint-Preux y las de la condesa de Castilla, citadas en el primer apartado de este trabajo. Tula de Avellaneda, en su novela $S a b$, de 1841, volverá a esta fórmula pasional y retórica cuando el personaje Carlota exclama: «iDios mío! [...] ¡si no es general esta terrible facultad de amar y padecer, cuán cruel privilegio me has concedido!... Porque es una desgracia, es una gran desgracia sentir de esta manera» (Gómez de Avellaneda, 1997: 133. Cursiva mía.). 
Estando ayer mañana sentado a la margen del río leyendo las Estaciones de Thomson y extasiado en sus sublimes descripciones... (carta 9).

Ahora mismo [Rosa] acaba de decirme que para merecer enteramente su aprecio he de corregir mi carácter, hacer muchas acciones virtuosas y calmar mi exaltacion (carta 9).

Un amigo mío, digno eclesiástico [...] se ha burlado a rienda suelta de mi amor, y de lo que él llama exageración de héroe de novela (carta 10).

Esa farsa de entes, que con una imaginación feliz y una cabeza cuyas fibras representativas están llenas de ideas trágicas y novelescas... (carta 10; habla el eclesiástico ya aludido).

El tedio de la soledad me consumía lentamente (carta 11)

- Voyleano, eres el mismo en todas las ocasiones. Te arrebatas, te exaltas, las imágenes toman aumento a tu vida, y no pasas de un miserable novelero. ¡Conque en vano procuro moderar tu carácter! ¡Ay, hijo mío! en el mundo se necesita de mucha calma (carta 11; Voyleano se imagina que Jerónimo le sermonea).

Te has abandonado a la lectura de libros demasiado fuertes para ti (carta 11; continuación del sermón imaginario).

¡Acaso he hecho otra cosa que seguir los impulsos de mi sensibilidad! ¿Son crímenes los pequeños extravíos de una imaginación fogosa? (carta 11).

¿Para qué vivir rabiando, desesperados, siempre ansiando el momento que no ha llegado, y sin disfrutar del presente! ¡Oh sepulcros! ¡Oh tranquilidad de vuestros moradores! ¿Qué es la existencia? Un tejido de desgracias, una cadena de infortunios... (carta 16; Voyleano en el cementerio).

Mas ¡ay! esta aparente tranquilidad es más funesta que los más acalorados arrebatos (carta 19).

El total desorden en que se halla mi imaginación, no me permite reflexionar sobre un asunto de que depende mi felicidad (carta 21).

...la fogosidad e ímpetu desarreglados de mi mente... (carta 22).

En la nota 1, al final del primer volumen de la novela, el autor de Voyleano se disculpa de haber incluido en su obra «doctrinas perniciosas que no he podido prescindir de poner en boca de un exaltado para manifestarlas tales como son».

....su intempestiva exaltación... (carta 28, Roberta, dirigiéndose al coronel, su padre, y comentando el estado de Voyleano).

Jamás las fibras de su cerebro se han visto tan desarregladas: la carta que ha escrito a su amigo manifiesta el desorden de su cabeza (carta 33; el cura comenta el estado del protagonista).

Sensibilidad, ternura, caracteres de las almas grandes yo os venero; sensaciones agradables, dejadme (carta 36, Voyleano a Jerónimo).

¿Cuántas veces después de cometer una mala acción me alababa yo juzgándola buena? He aquí, amigo querido, el gran principio de mi ruina: de aquí nació mi 
disolución, lo confieso con vergüenza, y cuando ningún remedio me queda. (carta 40, Voyleano a Jerónimo).

Días ha que su razón no está conforme (carta 47; la baronesa comenta el estado de Voyleano en carta al cura).

\section{VOYLEANO Y EL «PERSONAJE» VOYLEANO}

Cuando un hombre o una mujer se exalta, sale de sí, en cierto modo alzando el vuelo e imaginándose durante un momento llamado a rectificar alguna grave injusticia, o a ensalzar la hermosura de una catarata o un florido valle, por poner otro ejemplo. La exaltación se expresa por lo sublime. Cuando un prójimo nuestro se imagina desempeñando el papel de un admirado personaje histórico, dramático o novelístico, también sale de sí, impulsado por un vuelo aun más alto, aun más poético. En el Siglo de Oro Alonso Quijano se exalta, se vuelve loco buscando la inspiración de su vuelo poético en las empresas de los protagonistas de famosos libros de caballerías.

En nuestra selección de ejemplos de la exaltación de Voyleano, se dan varios ejemplos de la terminología novelística, con lo cual se sugiere la estrecha ilación existente entre estas dos formas de proyección de la personalidad sensible. Recordemos los ejemplos más interesantes para la comprensión de este paralelo: «entusiasmo novelesco» (carta 2); «la vehemencia de dos héroes de novela» (carta 4); «exageración de héroes de novela» (carta 10); «ideas trágicas y novelescas» (carta 10). Precisamente en la época en que se publica Voyleano o la exaltación de las pasiones, se renueva en la novela decimonónica un fascinante fenómeno psicológico, tan decisivo en la gran novela de Cervantes; y es que el héroe de novela vuelve a ser consciente de que es héroe de novela y de que él tiene su modelo o logos en un personaje novelístico anterior.

En un diálogo imaginario con Jerónimo en la carta 11, Voyleano supone que su amigo le dirige varias reprensiones: «No pasas de un miserable novelero»; y en fin: «Te has abandonado a la lectura de libros demasiado fuertes para ti», por ejemplo: el Werther, de Goethe, y las Noches lúgubres, de Cadalso. En la carta 19, el cura promete escribirle a Voyleano sobre «la causa de vuestra enfermedad novelera». En la carta siguiente, el cura sermonea al protagonista sobre su fatal afición a las novelas: «Con el mayor calor os dedicasteis a tan perniciosas lecturas, y vos mismo sin saberlo formasteis ese carácter novelero, que si Dios no lo remedia, os hará desgraciado [...] allí formasteis el loco empeño de que todos fuesen misántropos acabados» (carta 20). La baronesa logró luego de los señores del consejo que al prisionero Voyleano se le comunicase lo antes posible «la noticia de la muerte de su esposa, a fin de que el sentimiento calmase su novelesca imaginación» (carta 
46). Para nosotros Voyleano es el personaje titular de la novela de Vayo, pero para el mismo Voyleano él es en diferentes momentos el protagonista de Werther y de todas las novelas «perniciosas» que ha leído.

Hace un momento, decía que en el tiempo de Voyleano ciertos personajes novelísticos vuelven a reconocer que son tales creaciones basadas en modelos ilustres o infames. Por ejemplo, sobre Julien Sorel, protagonista de $L e$ Rouge et le Noir (1731), Stendhal escribe: «Certaines choses que Napoléon dit des femmes, plusieurs discussions sur le mérite des romans à la mode sous son règne, lui donnèrent alors, pour la première fois, quelques idées que tout autre jeune homme de son âge aurait eues depuis longtemps». Y dos capítulos más adelante, Julien hace una pregunta posiblemente decisiva: «C'était la destinée de Napoléon; serait-ce un jour la sienne?» (Stendhal, 1990: 74, 87) ${ }^{10}$.

Para sostener su teoría del logos literario de esos personajes que buscaban modelos psicológicos en las novelas anteriores, Américo Castro (1948) citaba el ejemplo de Julien Sorel y el del famoso personaje femenino Emma Bovary (1857), de Flaubert, quien aspiraba a emular las vidas de las heroínas románticas de las novelas que había leído, de los dramas que había visto, de los versos que recordaba. «Elle était l'amoureuse de tous les romans, l'héroine de tous les drames, le vague elle de tous les volumes de vers» (Flaubert, 1986: $338)^{11}$.

Mas en «El casarse pronto y mal» (1832), Larra nos da una Madame Bovary avant la lettre, un cuarto de siglo antes de editarse la novela de Flaubert, pues en dicho cuadro de costumbres la esposita de Augusto, Elena, «se embaucaba en su cuerpo, en sus ratos perdidos, que eran para ella todos los días, una novela sentimental con la más desatinada afición que en el mundo jamás se ha visto»; por tal «instrucción novelesca» se guiaba en todo, verbigracia, no guisando, porque «en cuanto a comer ni eso hacía falta a los enamorados, porque en ninguna novela se dice que coman las Amandas y los Mortimers, ni nunca les habían de faltar unas sopas de ajo»; y finalmente, acompañada por un amigo galante pero traicionero de su marido, Elena huyó de su descuidado hogar con las fatales consecuencias que sabe el lector de Fígaro (Larra, 1944: 61, 62, 62-63). En «El duelo» (1835), de Larra, se da otro ejemplo de conducta imitada de las novelas del tiempo: Adela «podía fingir admirablemente todo ese sentimentalismo, sin el cual no se alcanza en el día

${ }^{10}$ Traduzco: «Ciertas cosas que Napoleón dijo de las mujeres, varias discusiones sobre el mérito de las novelas de moda durante su reinado, le dieron luego, por la primera vez, algunas ideas que cualquier otro joven de su edad habría tenido desde hacía tiempo [...] Era el destino de Napoleón; ¿sería un día el suyo?»

${ }^{11}$ Traduzco: «Ella era la amorosa de todas las novelas, la heroína de todos los dramas, el vago ella de todos los volúmenes de verso». Existe en francés el término psicológico bovarysme, bovarismo, derivado del apellido de Emma Bovary. René Dumesnil lo define así: «Le bovarysme nous fait croire que nous sommes tels que nous voudrions être (El bovarismo nos hace creer que somos tales como quisiéramos ser)» (Dumesnil, 1932: 460). 
una sola victoria; cantaba con una languidez mortal; le miraba a usted con ojos de víctima expirante, siendo ella el verdugo» (Larra, 1944: 263). Y en «Una noche de vela», de Mesonero Romanos, que pertenece a la segunda serie (1836-1842) de las Escenas matritenses, la condesita del Tremedal, que «era grande apasionada de las heroínas de Balzac», entretiene a un militar joven y guapo mientras su marido se está muriendo (Mesonero Romanos, 1967: 113).

Todavía otra Madame Bovary anterior a la de Flaubert es Elvira, la mujer de Fernán Pérez de Vadillo en la novela romántica El doncel de don Enrique el Doliente (1834), de Larra, la cual se enamora de Macías y poetiza su infidelidad comparándose con el personaje Oriana en la novela Amadís de Gaula, cuya primera redacción circulaba en copias manuscritas en el siglo $\mathrm{XIV}$, tiempo en el que se supone acaecida la acción de dicha novela romántica:

Elvira simpatizaba no poco con las ideas de amor, constancia eterna y demás virtudes caballerescas que en aquel libro leía; hubiera dado la mitad de su existencia por hallarse en el caso de la bella Oriana, y aun no le faltaba a su imaginación ardiente un retrato de Amadís cuya fe la hubiera lisonjeado más que nada en el mundo; era éste un mancebo generoso [Macías] de la corte de Enrique III, a quien había conocido desgraciadamente después que a Fernán Pérez de Vadillo (Larra, 1978: 121).

Ahora bien: uno de los puntos de gran interés para el estudioso de la novela de 1827 titulada Voyleano o la exaltación de las pasiones es el hecho de que es anterior por su fecha de publicación a las de todos los ejemplos decimonónicos de personajes de logos que quedan citados. Voyleano ha leído Las cuitas del joven Werther, y así lleva en el alma el modelo psicológico del fatal personaje novelístico alemán. Queda dicho asimismo que Vayo/ Voyleano está al tanto de la historia europea de Werther, es decir, de los numerosos suicidios que esa novela había inspirado en los diversos países del continente. Vayan dos ejemplos: en enero de 1777, Christel von Lassberg se ahogó en el río Ilm, cerca de la casa de Goethe, y en un bolsillo del vestido de la desgraciada doncella se encontró un ejemplar de Werther (Garland, 1976: 518). En Bonn, un buen día se pegó un tiro el hijo de la adolorida señora Hohenhausen, dejando tras sí un ejemplar anotado del Werther de Goethe (Deleito, ¿1922?: 67). Al menos en literatura esa influencia había llegado asimismo al Nuevo Mundo: en 1789, en Boston, se publicó la novela The Power of Sympathy, de William Hill Brown, cuyo protagonista, Harrington, se pegó un tiro, y al lado del cadáver sangriento se descubrieron una carta y un ejemplar de Las cuitas de Werther (Brown, 1969: 175).

En Córdoba, en 1819, el hijo de una viuda analfabeta maltrataba a sus hermanitos y amenazaba quitarse la vida. ¿Cuál era la causa de tan preocupante conducta? El joven sin interrupción tenía la cara metida en un pequeño libro. Un vecino lo leyó a petición de la desesperada madre y lo denunció ante el tribunal de la Inquisición. Eran las Noches lúgubres, de Cadalso, y se con- 
denó el diminuto libro por «contener muchas expresiones escandalosas, peligrosas e inductivas al suicidio, al desprecio de los padres y al odio general de todos los hombres» (Helman, 1951: 44; cursiva mía). Nuevo incentivo a la muerte voluntaria, y el acompañante «odio general de todos los hombres» es un síntoma del fastidio universal. Tal era el ambiente internacional y español en el que se inspiró la historia del malaventurado y deseoso de morir Voyleano.

El texto novelístico del escritor valenciano revela su obsesión por el malsano pensamiento de la muerte voluntaria. Y de esta vertiente de la psique del novelista es evidentemente proyección la psicología del protagonista Voyleano, que lucha repetidamente entre su voluntad de morir y su horror al acto físico del suicidio por parecerle una cobardía indigna, y en fin poco noble. He aquí un Werther español, pero nada católico, porque lo que le hace vacilar ante el acto de la muerte voluntaria no son escrúpulos religiosos. Pues Voyleano es un atormentado descendiente de la Ilustración con su vacilante escepticismo ante la religión, que él llama «exaltación de ideas», en la carta 3.

Quien se siente vacío ya está muerto psicológicamente.

¡Ay de mí! ¡Este vacío, este horrible vacío que siente mi alma...!»—exclama Werther en su carta del 19 de octubre- Sólo Dios sabe cuántas veces me he dormido con el deseo y la esperanza de no despertar más — sigue reflexionando el desesperado personaje alemán-. Y al día siguiente, abro los ojos, vuelvo a ver la luz del sol y siento de nuevo el peso de mi miseria [...] Bastante es ya que lleve en mí la fuente de todos los dolores (Goethe, 1973: 149, 152).

Llámase Sturm und Drang - Tempestad y Empuje- el movimiento literario en cuyo seno nació la obra de Goethe en 1774. Y en el propio Werther trátase de la enfermedad que se llamará en sus respectivos países «fastidio universal», «mal du siècle» y «Weltschmerz»; y este vacío del alma — «la fuente de todos los dolores»— es en sí suficiente causa para tentarse por el suicidio, aunque no interviniera ningún problema amoroso. En el fondo poco importa el imposible amor de Werther por Carlota cuando se busca el motivo del suicidio del desilusionado galán. Voyleano tiene dos amadas, ambas muertas en el curso de sus trágicas aventuras, y poco importan las tristes existencias y defunciones de Leonor y Roberta al buscarse el motivo de la impertérrita voluntad de morir que persiste en Voyleano.

Hemos dicho que es en realidad el mal du siècle — su absoluta falta de comodidad en su mundo y tiempo- lo que lleva a la muerte de Werther. «Es cosa resuelta, Carlota: quiero morir, y te lo participo sin ninguna exaltación romántica» (Goethe, 1973: 187; cursiva mía), donde un negativo vale por un positivo de grado superlativo. En el mismo decenio de 1770 esta queja plagaba a otros doloridos poetas. En 1771 Cadalso compone sus Noches lúgubres; y en 1777 Meléndez Valdés capta todo esto perfectamente en un solo endecasílabo, que hace temblar: «Huérfano, joven, solo y desvalido» (Melén- 
dez Valdés, 2004: 565). Voyleano era lector de Meléndez Valdés, según se revela en la carta 18. En el nuevo siglo XIX se intensificaría la enfermedad de la existencia, la exaltación nerviosa de quien no se adapta a las circunstancias de la vida en este mundo, y ya en su carta tercera Voyleano trazó estas espantosas líneas, que casi podrían ser manifiesto de la nueva generación romántica. El lector ya las conoce. Mas éste es su verdadero sitio.

Mi exaltación de ideas crece de día en día, y cada instante encuentro mayor grado de sensibilidad en mí. Esclavizando los sentidos con los sentimientos vehementes que despierta en la inocente juventud, crea en nuestros corazones una enfermedad más peligrosa que la misma fiebre. Ésta se puede atajar, ;pero aquélla es tan difícil si toma incremento! ¡Concebir grandezas y vernos cercados de humillaciones!

En la carta 11, se reitera esto cuando Voyleano imagina que su amigo Jerónimo le sermonea: «Tú adoleces de una enfermedad muy peligrosa». La solución de tan horrorosa incomodidad en este planeta - lo que Werther llama «todas las cuitas de mi corazón» (Goethe, 1973: 211) — es evidentemente salirse de él. Werther de hecho se suicidó. Decía algún tiempo antes: «No veo para esta mísera existencia otro fin que el sepulcro» (Goethe, 1973: 101). ¿Se suicidó, o no se suicidó Voyleano? También algún tiempo antes de su hora suprema Voyleano aspiraba a la extinción: «Pintan horrorosa la muerte, iy es tan hermosa cuando se desea!» (carta 18). En la carta siguiente Voyleano recuerda algo que le decía el cura: «Os habéis suicidado ya, porque en nada se diferencia un muerto que yace en el sepulcro, de un vivo que yace en la inacción». No vacila Voyleano en su fascinación por la muerte voluntaria debido a ningún escrúpulo católico que el cura le haya infundido. Entonces, ¿por qué no quiere tomar directamente en mano el arma de fuego para borrar sus cuitas mundanales? Lejos de ver en el suicidio un pecado mortal, dice una y otra vez que es un acto cobarde, nada noble. Por ejemplo, en la carta 13, dirigida a Jerónimo, escribe: «Mis sentimientos siempre han sido muy nobles; no temas que sea tan cobarde que me suicide».

En el segundo apartado de este trabajo hemos recordado que hacia el final de la novela Voyleano organiza un motín en la prisión francesa. Es más: delante de los soldados del rey francés de España, José I Bonaparte, Voyleano elogia fervorosamente a Fernando VII; y ya hemos dicho que al ofrecérsele por segunda vez la oportunidad de confesarse, no la aprovechó. Rechazar la confesión a la hora de la muerte es profesar el descreimiento de los descendientes escépticos de la Ilustración. Consecuencia de la rebeldía e insubordinación de Voyleano es su ya mencionada muerte ante un pelotón de fusilamiento. Con su muy hábil provocación de los sucesos en la prisión, Voyleano se ha suicidado por una forma de lo que hoy llamaríamos mando a distancia, y por tanto su muerte no es menos el resultado de sus actos que si se hubiera matado con su pistola en la mano. Lo confiesa así Voyleano, en la carta 47: «Lo único que me propuse lo he conseguido: acelerar mi muerte. 
Quería morir, pero soy enemigo por principios del suicidio, y es en mi concepto la mayor de las cobardías» (la cursiva es mía).

Voyleano muere a voluntad sin necesidad de presionar el gatillo del arma de fuego que corta sus días; suicidio sin suicidarse con la propia mano, y esto tiene un interesante antecedente español, en las Noches lúgubres, el ya mencionado poema en prosa dialogada de Cadalso. Tediato se proponía abrir la tumba de su amada, llevar los restos de la dama a su casa, herirse de muerte, incendiar su morada y morir junto al cadáver un tiempo hermoso, ahora horroroso; una variante del suicidio doble de los enamorados infelices. Le fallan sus intentos de ejecutar el espantoso plan las dos primeras noches, y la tercera noche el poema termina in medias res: "Andemos, amigo, andemos», le dice Tediato al sepulturero Lorenzo que viene asistiéndole (Cadalso, 2008: 410). ¿Seguirá Tediato en sus intentos de exhumar a la beldad de los cabellos de oro, convertida en comida de los gusanos que el antiguo amante ha visto en el borde del sepulcro medio abierto? ¿O simplemente contemplará Tediato la posibilidad de seguir en esos intentos? El tema de las Noches lúgubres es la contemplación del suicidio y su proceso - que es un suicidio lento y repetido-, más bien que el acto del suicidio. Sin llegar a arremeter contra sus días Tediato se ha creado una forma de muerte en vida o refugio mortuorio en este mundo, en donde puede gozar de su dolor e imaginarse su muerte. Al menos durante algún tiempo, ese mismo goce lo conocerá Voyleano: «Mi corazón vive para el desconsuelo; él me convida a la desesperación», confía el protagonista a su amigo Jerónimo (carta 14). Trozo que el lector conoce desde el segundo epígrafe de este trabajo.

De no haber desdeñado todos los fantasmas y aparecidos por su postura de pensador escéptico de la Ilustración, Tediato seguramente habría recibido una visita del espectro de su amada muerta semejante a la que Voyleano lograría de su Leonor, sepultada ya desde algún tiempo. Lo que me interesa en el trozo siguiente no es tanto su contenido específico como su tonalidad claroscura ominosa, semejante, por ejemplo, a la de la descripción que Tediato hace de su amante, muerta y sepultada desde hace algún tiempo ya:

La muerte tomó la forma de Leonor... y en su figura... Aún la veo: sus ojos centellean rayos de venganza, su frente amarillea con el color del sepulcro, aquellos lívidos labios, donde un día bebí ambrosías celestiales, se abren para anunciarme que llegó la hora destinada por la Omnipotencia para mi castigo (carta 34).

He aquí la esencia de la descripción que hace Tediato de su adorada difunta, al final de la primera noche:

¡De tus hermosos ojos se han engendrado vivientes asquerosos! ¡Tu pelo, que en lo fuerte de mi pasión llamé mil veces no sólo más rubio, sino más precioso que el oro, ha producido esta podre! [...] Objeto antiguo de mis delicias... ¡Hoy objeto de horror para cuantos te vean! Montón de huesos asquerosos... En otros tiempos, conjunto de gracias! Oh tú, ahora imagen de lo que yo seré en breve; pronto volveré a tu tumba (Cadalso, 2008: 383-384, 386). 


\section{BIBLIOGRAFÍA CITADA}

Álvarez de Cienfuegos, Nicasio (1798). Poesías. T. I y único. Madrid: Imprenta Real.

Brown, William Hill (1969). The Power of Sympathy. Ed. de William S. Kable. Columbus: Ohio State University Press.

Cadalso, José de (2008). Cartas marruecas. Noches lúgubres. Ed. de Russell P. Sebold. Letras Hispánicas, 78. Séptima edición. Madrid: Ediciones Cátedra.

Castro, Américo (1948). «Incarnation in Don Quixote». Cervantes Across the Centuries. New York: The Dryden Press. pp. 136-178.

Cooper, Anthony Ashley, Earl of Shaftesbury (1964). The Moralists. En Characteristics of Men, Manners, Opinions, Times. Indianapolis: Bobbs-Merrill.

Compact Edition of the Oxford English Dictionary (1971). Oxford: Oxford University Press.

Deleito y Piñuela, José (¿1922?). El sentimiento de tristeza en la literatura contemporánea. Barcelona: Editorial Minerva.

Dubos, Abbé Jean-Baptiste (1770). Réflexions critiques sur la poésie et sur la peinture. Paris: Pissot, Imprimeur.

Dumesnil, René (1932). Gustave Flaubert, l'homme et l'oeuvre. Paris: Desclée de Brouwer \& Compagnie, Éditeurs.

Feijoo y Montenegro, Benito Jerónimo (1770). «Despotismo o dominio tiránico de la imaginación», en Benito Jerónimo Feijoo y Montenegro, Cartas eruditas y curiosas. T. IV. Nueva impresión. Madrid: Joaquín Ibarra, impresor, pp. 82-90.

Flaubert, Gustave (1986). Madame Bovary. Ed. de Bernard Ajac. Paris: GF Flammarion.

Garland, Henry and Mary (1976). The Oxford Companion to German Literature. Oxford: Clarendon Press.

Goethe, J. W. (1973). Werther. Prólogo de Carmen Bravo Villasante. Biblioteca Universal Salvat. Traducción cedida por Revista de Occidente. [Barcelona:] Salvat Editores, S. A.

Gómez de Avellaneda, Gertrudis (1997). Sab. Ed. de José Servera. Letras Hispánicas, 437. Madrid: Ediciones Cátedra.

Helman, Edith (1951). Introducción a Cadalso, Noches lúgubres. El Viento Sur, 7, SantanderMadrid: Antonio Zúñiga, Editor.

Jovellanos, Gaspar Melchor (2008). El delincuente honrado. Ed. de Russell P. Sebold. Letras Hispánicas, 612. Madrid: Ediciones Cátedra.

Larra, Mariano José de (1944). Artículos completos. Ed. de Melchor de Almagro San Martín. Madrid: Aguilar.

Larra, Mariano José de (1978). El doncel de don Enrique el Doliente. Ed. de José Luis Varela. Letras Hispánicas, 76. Madrid: Ediciones Cátedra.

Meléndez Valdés, Juan (2004). «A la mañana, en mi desamparo y orfandad». Obras completas. Ed. de Antonio Astorgano Abajo. Bibliotheca Aurea. Madrid: Ediciones Cátedra. pp. 564-566.

Mesonero Romanos, Ramón de (1967). Obras, II. Ed. de Carlos Seco Serrano. Biblioteca de Autores Españoles, 200. Madrid: Atlas.

Robeck, Johann (1736). Exercitatio philosophica de $\varepsilon v \lambda \circ \gamma \omega \varepsilon \xi \alpha \gamma \omega \gamma \eta$ sive morte voluntaria. Reeditado en 1758. [Sin lugar:] Rintelli.

Rodríguez, Rodney (1988). «Estanislao de Cosca Vayo and the Fate of the Spanish Romantic Novel». Romance Quarterly. 35, pp. 271-279.

Rousseau, Jean-Jacques (1967). Julie ou la Nouvelle Hélö̈se. Ed. de Michel Launay. Paris: Garnier-Flammarion.

[Sajonia, María Josefa Amalia de] (1822). Cartas de la reina Witinia a su hermana, la princesa Fernandina. Madrid: Imprenta de D. Miguel de Burgos.

Sebold, Russell P. (2004). Ensayos de meditación y crítica literaria. Moria, 5. Salamanca: Ediciones Universidad de Salamanca. 
Sebold, Russell P. (2007). En el principio del movimiento realista. Credo y novelística de Ayguals de Izco. Crítica y Estudios literarios. Madrid: Ediciones Cátedra.

Sebold, Russell P. (2010a). Concurso y consorcio: letras ilustradas, letras románticas. Acta Salmanticensia, Estudios Filológicos, 329. Salamanca: Ediciones Universidad de Salamanca.

Sebold, Russell P. (2010b). «Romanticismo en la novela realista: Dos mujeres, de la Avellaneda», Salina. 24, pp. 27-37.

Sebold, Russell P. (2011). «Elegía al romanticismo: La Pródiga, de Alarcón». Boletín de la Biblioteca de Menéndez Pelayo. LXXXVII, pp. 173-185.

Stendhal [Henri Beyle, llamado] (1990). Le Rouge et le Noir. Ed. de Pierre Louis Rey. Paris: Pocket.

Terreros y Pando, Esteban de (1788). Diccionario castellano con las voces de ciencias y artes. T. III. Madrid: Imprenta de la Viuda de Ibarra, Hijos y Compañía.

Vayo y Lamarca, Estanislao de Cosca (1826). Ensayos poéticos. Valencia: Oficina de Benito Monfort.

Vayo y Lamarca, Estanislao de Cosca (1827). Voyleano o la exaltación de las pasiones. Dos tomos. Valencia: Imprenta de Ildefonso Mompié.

Vayo y Lamarca, Estanislao de Cosca (2007). Voyleano o la exaltación de las pasiones. Edición, introducción y notas de Mark Malin. Salamanca: GES XVIII (Universidad de Salamanca).

Vayo y Lamarca, Estanislao de Cosca (2011). Voyleano o la exaltación de las pasiones. Facsímile de la edición de 1827. Estados Unidos: Nabu Press.

Zavala y Zamora, Gaspar (1805). La Eumenia, o la madrileña. Madrid: Imprenta Real.

Fecha de recepción: 12 de abril de 2013

Fecha de aceptación: 21 de octubre de 2013 